\title{
Multilayered ZnO Films of Improved Quality Deposited by Magnetron Sputtering
}

\author{
A. Ievtushenko ${ }^{a}, \mathrm{~V}$. Karpyna ${ }^{a}, \mathrm{G}$. LashkareV ${ }^{a}$,

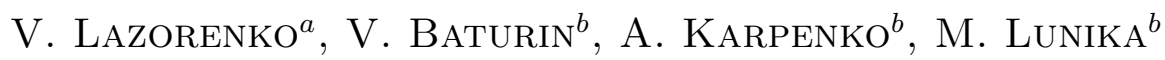 \\ AND A. DAN'KO ${ }^{c}$ \\ ${ }^{a}$ Institute for Problems of Material Science, NASU \\ 3 Krzhizhanovskogo st., Kiev, 03680, Ukraine \\ ${ }^{b}$ Institute of Applied Physics, NASU \\ 58 Petropavlovskaya st., Sumy, 40030, Ukraine \\ ${ }^{c}$ SSI "Institute for Single Crystals", NASU \\ 60 Lenin Ave., Kharkov, 61001, Ukraine
}

\begin{abstract}
Multilayered $\mathrm{ZnO}$ films were deposited by rf magnetron sputtering on silicon and sapphire substrates. The aim of this work is to improve structural quality of $\mathrm{ZnO}$ thin films grown on just listed substrates. Presented X-ray diffraction data testify to remarkable relaxation of compressive stress in twoand three-layered $\mathrm{ZnO}$ films in comparison with single-layer one.
\end{abstract}

PACS numbers: 81.05.Dz, 81.15.Cd, 61.05.cp, 68.55.jm

\section{Introduction}

In recent years a great attention has been paid to a wide gap semiconductor $\mathrm{ZnO}\left(E_{\mathrm{g}}=3.37 \mathrm{eV}\right.$ at room temperatures). Like other wide-gap semiconductors, $\mathrm{ZnO}$ can be used to develop light emitting devices and detectors for blue and ultraviolet range of spectrum. Compared to well-known $\mathrm{GaN}, \mathrm{ZnO}$ has a large exciton binding energy $(60 \mathrm{meV})$ that allow to provide effective excitonic stimulated emission at room and higher temperatures. Thus, high quality $\mathrm{ZnO}$ films deposited by molecular beam epitaxy (MBE) demonstrate the so-called "lasing" at optical excitation with small lasing threshold [1].

Substrate material plays the key role in obtaining high quality $\mathrm{ZnO}$ layers. Usually ZnO films are deposited on glass, quartz, silicon and sapphire substrates. However, glass substrates are practically nasty for qualitative $\mathrm{ZnO}$ film growth. 
Deposition on such substrates starts with a formation of $\mathrm{ZnO}$ amorphous layer. When it reaches some threshold thickness, formation of polycrystalline $\mathrm{ZnO}$ film layer takes place [2]. Thus, the quality of the film deposited on glass substrate is not high. The most suitable substrate for $\mathrm{ZnO}$ growth is $\mathrm{ScAlMgO}_{4}$ (misfit of lattice periods $0.09 \%$ ). As it is stated in [3] $\mathrm{ScAlMgO}_{4}$ allows a growth of high structural quality $\mathrm{ZnO}$ films. It results in high carrier mobilities $\left(60-100 \mathrm{~cm}^{2} /(\mathrm{V} \mathrm{s})\right)$ and low carrier concentrations $\left(4-27 \times 10^{15} \mathrm{~cm}^{-3}\right)$. However, such substrates are expensive and technologically inconvenient. Some troubles arise at using $\mathrm{Si}$ and $\mathrm{Al}_{2} \mathrm{O}_{3}$ substrates for $\mathrm{ZnO}$ epitaxial growth. Lattice period of silicon and sapphire have large misfits with lattice period of hexagonal $\mathrm{ZnO}(\approx 41 \%$ and $\approx 18 \%$, respectively) [4]. Moreover, Si undergoes oxidation in argon-oxygen ambient at $\mathrm{ZnO}$ growth and therefore formation of amorphous $\mathrm{SiO}_{x}$ layer occurs [5]. This layer causes deterioration of the crystal quality of growing $\mathrm{ZnO}$ layer. Also Si extracts oxygen from $\mathrm{ZnO}$ lattice at post-growth annealing which leads to formation of oxygen vacancies $\mathrm{V}_{\mathrm{O}}$. Therefore it results in a poor UV photoluminescence of $\mathrm{ZnO} / \mathrm{Si}$ films [6].

One way to obtain high quality $\mathrm{ZnO}$ layers on $\mathrm{Si}$ and sapphire substrates is to use buffer layers such as GaN, AlN, ZnS. However, at high substrate temperatures $450-750^{\circ} \mathrm{C}$, high quality $\mathrm{ZnO}$ films can be deposited without buffer layers by advanced technique such as MBE [7]. Crystal quality of $\mathrm{ZnO}$ films was estimated by film stress value $\sigma$.

In present paper we investigate structural quality of $\mathrm{ZnO}$ films deposited by magnetron sputtering on Si and sapphire substrates. Effect of substrate temperature on a quality of $\mathrm{ZnO}$ film was also studied. We suppose that the layer by layer growth method, at which $\mathrm{ZnO}$ homoepitaxy takes place, can significantly improve film quality as a whole.

\section{Experimental procedure}

Thin multilayered $\mathrm{ZnO}$ films with thicknesses about $300 \mathrm{~nm}$ were deposited by rf magnetron sputtering. The metallic $\mathrm{Zn}$ was used as a target. Substrate temperatures $T_{\mathrm{s}}$, argon and oxygen partial gas pressure, rf discharge power, and target-substrate distance are the parameters that greatly influence on structural properties of growing $\mathrm{ZnO}$ film. But only the effect of substrate temperature was investigated. Other parameters were fixed: discharge power $-200 \mathrm{~W}$, oxygen partial pressure $-0.2 \mathrm{~Pa}$, argon partial pressure $0.8 \mathrm{~Pa}$, target-substrate distance $-7 \mathrm{~cm}$

Multilayered $\mathrm{ZnO}$ films were deposited in layer by layer mode i.e. process of growth of $\mathrm{ZnO}$ film was carried out in several stages. At the next stage of film deposition we keep all mentioned parameters fixed and change only substrate temperature. After deposition of every single $\mathrm{ZnO}$ layer deposition process was interrupted and X-ray diffraction (XRD) measurements were carried out. Thus, the process of layer by layer growth represents a deposition of next $\mathrm{ZnO}$ film on $\mathrm{ZnO}$ film already grown on substrate. Therefore the substrate significantly impacts 
only on nucleation and growth of the first $\mathrm{ZnO}$ layer. Next $\mathrm{ZnO}$ layers grow in homoepitaxy conditions. Using this deposition procedure we obtain one-, two- and three-layered $\mathrm{ZnO}$ films. Multilayered $\mathrm{ZnO}$ films were deposited on $\mathrm{Si}$ (100) and $c$-sapphire (0001) substrates. For comparison we deposited one layer $\mathrm{ZnO}$ films on glass substrate as well as on $a$ - and $r$-cuts of sapphire substrates.

Crystal quality of multilayered $\mathrm{ZnO}$ films was investigated by XRD diffractometer DRON-4 $\left(\mathrm{Cu} K_{\alpha}\right.$ radiation with wavelength $\left.\lambda=0.1541 \mathrm{~nm}\right)$. The peak positions were compared with reference data from powder diffraction file for $\mathrm{ZnO}$ [8]. Scherrer's formula was used to determine grain size

$$
D=\frac{0.9 \lambda}{W \cos \theta},
$$

where $D$ - average grain size, $W$ - full width at half maximum (FWHM) in radians, $\theta$ - Bragg's angle.

$\mathrm{ZnO}$ film stresses were evaluated accordingly [9] by the following formula:

$$
\sigma=-233 \frac{c-c_{0}}{c},
$$

where $\sigma$ is the film stress (GPa); $c$ is the lattice period determined from interplanar spacing $d$ of $(002)$ reflex $(c=2 d) ; c_{0}=0.5206 \mathrm{~nm}$ - lattice period for $\mathrm{ZnO}$ powder [8].

\section{Results and discussion}

Figure 1 shows XRD spectra for $\mathrm{ZnO}$ films deposited at the same technological conditions on various kinds of substrates. Silicon and glass substrates as well as $a$ - and $c$-sapphire substrates provide $\mathrm{ZnO}$ growth in $\langle 001\rangle$ direction i.e. $c$-axis of $\mathrm{ZnO}$ is perpendicular to substrate plane. Growth along $c$-axis is inherent to $\mathrm{ZnO}$ having hexagonal crystal lattice with lowest free energy for (0001) plane [4]. However, depending on deposition conditions (especially $T_{\mathrm{s}}$ ) crystallites of polycrystalline $\mathrm{ZnO}$ film can have other orientations. Thus, either textured or untextured films can be obtained. In the case of $T_{\mathrm{s}}=300^{\circ} \mathrm{C}$ that allowed us to grow polycrystalline textured $\mathrm{ZnO}$ films on oriented $\left(\mathrm{Si}, \mathrm{Al}_{2} \mathrm{O}_{3}\right)$ as well as on amorphous (glass) substrates. As can be seen from Fig. 1 oriented substrates provide good high textured film growth (intensive peaks with low FWHM). Most intensive peak (002) was observed for $\mathrm{ZnO}$ films grown on $c$-sapphire as a result of similar crystal structure for $\mathrm{ZnO}$ and $\mathrm{Al}_{2} \mathrm{O}_{3}$. $\mathrm{ZnO}$ grown on $a$-cut of $\mathrm{Al}_{2} \mathrm{O}_{3}$ also have orientation $\langle 0001\rangle$ accordingly to epitaxial relationship $(0001) \mathrm{ZnO}_{\mathrm{ZnO}} / /(11 \overline{2} 0)_{\mathrm{Al}_{2} \mathrm{O}_{3}}$ [4]. But $\mathrm{ZnO}$ film grown on $r-\mathrm{Al}_{2} \mathrm{O}_{3}$ has another texture (110) accordingly to relationship $(11 \overline{2} 0)_{\mathrm{ZnO}} / /(01 \overline{1} 2)_{\mathrm{Al}_{2} \mathrm{O}_{3}}$. Table summarizes XRD data of $\mathrm{ZnO}$ films shown in Fig. 1. Notably, $\mathrm{ZnO}$ films deposited by magnetron sputtering have fine grain structure with grain size in the range $16-26 \mathrm{~nm}$. The strongest deformation of $\mathrm{ZnO}$ lattice was observed in $\mathrm{ZnO} / \mathrm{Si}$ films as a result of large lattice misfit $(\approx 41 \%)$ [4]. 


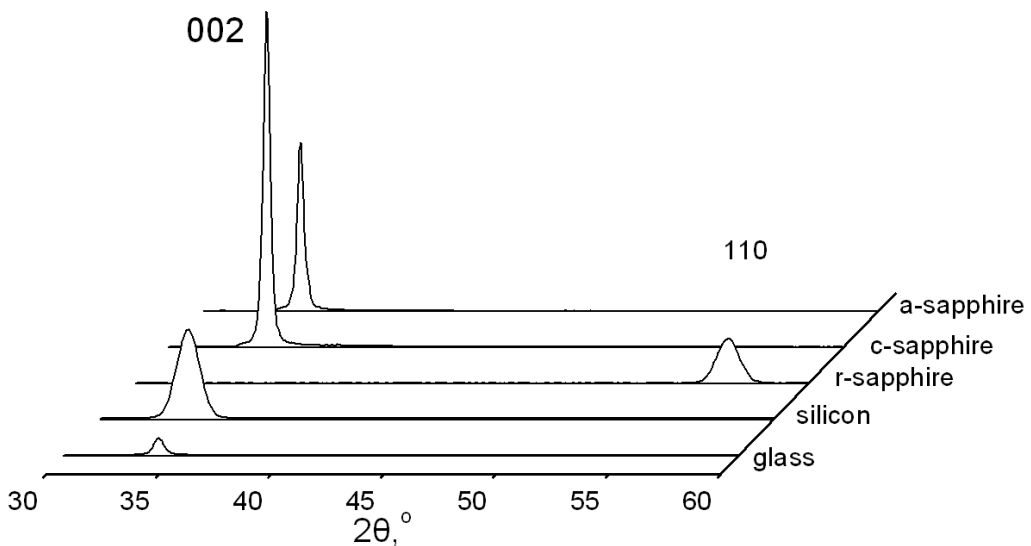

Fig. 1. XRD spectra of $\mathrm{ZnO}$ films deposited on various substrates at $T_{\mathrm{s}}=300^{\circ} \mathrm{C}$.

TABLE

XRD parameters of $\mathrm{ZnO}$ films shown in Fig. 1 .

\begin{tabular}{c|c|c|c|c|c}
\hline \hline Substrate & $\begin{array}{c}\text { Peak position 2 } \\
\text { (texture) [degree] }\end{array}$ & $\begin{array}{c}c \\
{[\mathrm{~nm}]}\end{array}$ & $\begin{array}{c}W \\
{[\text { degree] }}\end{array}$ & $\begin{array}{c}\sigma \\
{[\mathrm{GPa}]}\end{array}$ & $\begin{array}{c}D \\
{[\mathrm{~nm}]}\end{array}$ \\
\hline$a-\mathrm{Al}_{2} \mathrm{O}_{3}$ & $34.313(002)$ & 0.522 & 0.34 & -0.63 & 24 \\
$c-\mathrm{Al}_{2} \mathrm{O}_{3}$ & $34.359(002)$ & 0.521 & 0.32 & -0.33 & 26 \\
$r-\mathrm{Al}_{2} \mathrm{O}_{3}$ & $56.375(110)$ & - & 0.62 & - & 23 \\
$\mathrm{Si}$ & $33.96(002)$ & 0.528 & 0.47 & -2.9 & 16 \\
glass & $34.213(002)$ & 0.524 & 0.48 & -1.29 & 17
\end{tabular}

We investigated the possibility of obtaining more perfect $\mathrm{ZnO}$ films by formation of two and three $\mathrm{ZnO}$ layers during consecutive stages of deposition. We have deposited the first $\mathrm{ZnO}$ layer with thickness about $200 \mathrm{~nm}$ on Si substrates, having a large lattice misfit. The second and the third $\mathrm{ZnO}$ layers had thicknesses about $50 \mathrm{~nm}$ each. Figure 2 shows XRD data for multilayered $\mathrm{ZnO} / \mathrm{Si}$ films. As can be seen, layer by layer technique for $\mathrm{ZnO}$ film deposition leads to improving of film quality. Thus, reflex from (002) planes of $\mathrm{ZnO}$ lattices tends to $2 \theta=34.42^{\circ}$ that is the reference value for (002) plane of $\mathrm{ZnO}$ powder [8]. At that, relaxation of compressive stress in films was observed (Fig. 2b).

Figure 3 shows the dependences for $\sigma$ and lattice period $c$ of two-layered $\mathrm{ZnO}$ film on substrate temperature at deposition of the second layer. Variation of substrate temperature in the range $200-350^{\circ} \mathrm{C}$ at deposition of the second $\mathrm{ZnO}$ layer slightly influences on $\mathrm{ZnO} / \mathrm{Si}$ film quality. $\mathrm{ZnO}$ films deposited at $T_{\mathrm{s}}=250^{\circ} \mathrm{C}$ have the least lattice deformation and the smallest value of $\sigma$. At deposition the third $\mathrm{ZnO}$ layer at $T_{\mathrm{s}}<300^{\circ} \mathrm{C}$ other insignificant peaks corresponding to (100) and (101) crystalline orientation in XRD spectra appeared. Thus high quality 


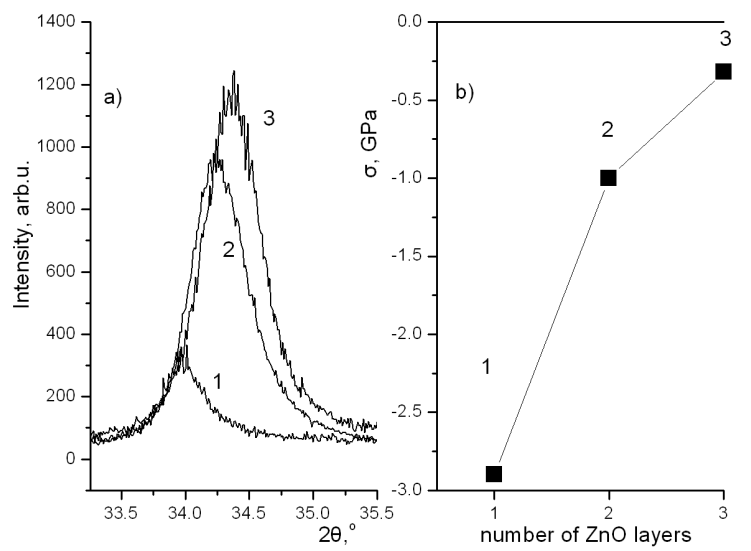

Fig. 2. XRD spectra for multilayered $\mathrm{ZnO} / \mathrm{Si}$ films (a) and stress in the films (b) ( $\mathrm{ZnO}$ films of: 1 - one-layer, 2 - two-layer and 3 - three-layer).

multilayered $\mathrm{ZnO}$ films on silicon substrates can be grown at substrate temperature $300^{\circ} \mathrm{C}$ by the process of layer by layer growth.

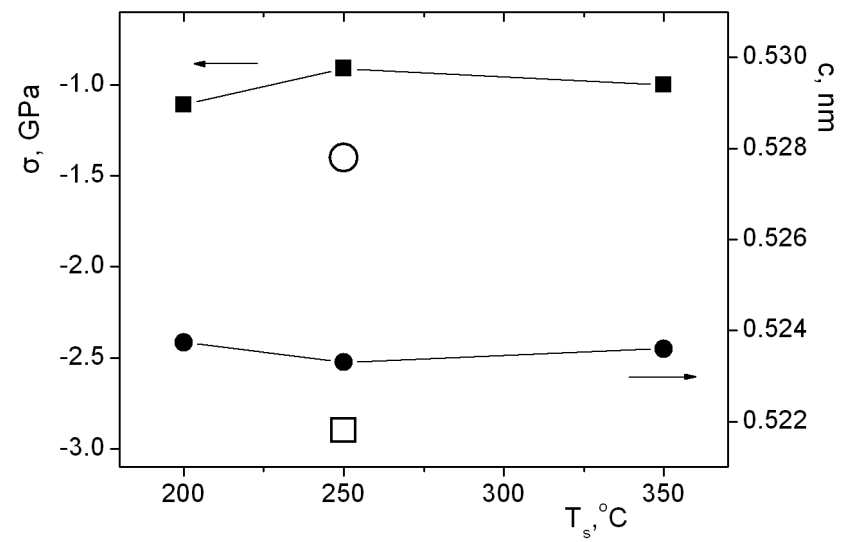

Fig. 3. Dependences of film stress $\sigma$ and lattice period $c$ for two-layered $\mathrm{ZnO} / \mathrm{Si}$ films on substrate temperature $T_{\mathrm{s}}$ after growing the second $\mathrm{ZnO}$ layer $(\bullet-\operatorname{period} c$, film stress $\sigma$ ). Open symbols $\circ$ and $\square$ denotes $c$ and $\sigma$ for initial (one-layer) $\mathrm{ZnO} / \mathrm{Si}$ film deposited at $T_{\mathrm{s}}=250^{\circ} \mathrm{C}$.

Multilayered $\mathrm{ZnO}$ films of total thicknesses about $300 \mathrm{~nm}$ were also deposited on $c$-sapphire substrates. Figure 4 a shows XRD spectra of $\mathrm{ZnO} / \mathrm{Al}_{2} \mathrm{O}_{3}(0001)$ films. Film stress dependence on substrate temperature at deposition each single layer of $\mathrm{ZnO}$ is represented in Fig. 4b.As can be seen from Fig. 4b three-layered ZnO films display total relaxation of compressive stress. Parameter $\sigma$ becomes positive that testify to the formation of low tensile stress. It should be noted that intermediate $\mathrm{ZnO}$ layer, deposited at $T_{\mathrm{s}}=200^{\circ} \mathrm{C}$ have a stress. Besides that one can see that 


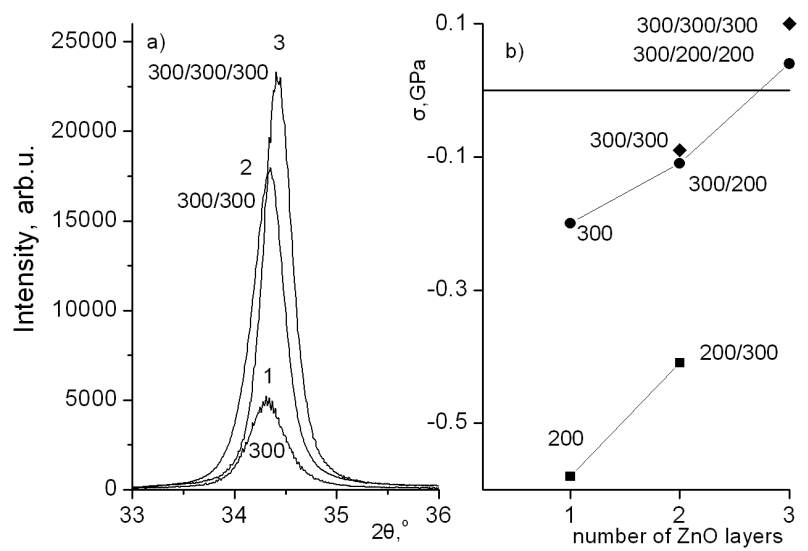

Fig. 4. XRD spectra for multilayered $\mathrm{ZnO} / \mathrm{Al}_{2} \mathrm{O}_{3}(0001)$ films (a) and stress in the films (b). 1, 2, 3 - number of $\mathrm{ZnO}$ layers. Substrate temperature is pointed at growing of each layer ( $T_{\mathrm{S}}$ of first layer $/ T_{\mathrm{S}}$ of second layer $/ T_{\mathrm{S}}$ of third layer).

one-layer $\mathrm{ZnO}$ films deposited at $T_{\mathrm{s}}=300^{\circ} \mathrm{C}$ have less stress compared to the film deposited at $T_{\mathrm{s}}<300^{\circ} \mathrm{C}$ (including multilayered), and therefore, a higher crystal quality.

To elucidate the effect of film thicknesses on film stress relaxation we investigated the film stress in two $\mathrm{ZnO}$ films deposited at $T_{\mathrm{s}}=300^{\circ} \mathrm{C}$ during $0.5 \mathrm{~h}$ and $1 \mathrm{~h}$, respectively. ZnO films have compressive stress $-0.33 \mathrm{GPa}$ and $-0.2 \mathrm{GPa}$, respectively. Though film stress decreases at growing film (i.e. at increase in thickness), we could not obtain non-stressed $\mathrm{ZnO}$ film during one stage of deposition even at high growth temperature $\left(300^{\circ} \mathrm{C}\right)$. Thus, applying process of layer by layer growth, textured non-stressed $\mathrm{ZnO}$ films on $\mathrm{Al}_{2} \mathrm{O}_{3}(0001)$ substrate by magnetron sputtering system were obtained.

Homoepitaxy of $\mathrm{ZnO}$ was studied in [10] at deposition $\mathrm{ZnO}$ film on thin $\mathrm{ZnO}$ buffer layer. As a result the structural quality of these films has been improved. We assume that improving of film perfectness is due to smaller misfit between $\mathrm{ZnO}$ layers. It results in homoepitaxy and relaxation of strain in multilayered films with increasing number of $\mathrm{ZnO}$ layers even when thickness of next $\mathrm{ZnO}$ layer is not large $(50 \mathrm{~nm})$. Indeed, top layer of multilayered $\mathrm{ZnO}$ films is of very high structural quality compared to underlying $\mathrm{ZnO}$ layers. As a result, in XRD spectra we observed very intensive peak (002) obliged mainly top $\mathrm{ZnO}$ layers.

\section{Summary}

Multilayered $\mathrm{ZnO}$ films were deposited by magnetron sputtering on $\mathrm{Si}$ and sapphire substrate. One-layer $\mathrm{ZnO}$ films are characterized by a presence of residual stress. Applying layer by layer growth method, one obtains $\mathrm{ZnO}$ films of an improved quality which results in significant increasing intensity of diffraction peaks, lowering FWHM and lowering or disappearance of stresses in $\mathrm{ZnO}$ films. 


\section{References}

[1] Z.K. Tang, G.K.L. Wong, P. Yu, M. Kawasaki, A. Ohtomo, H. Koinuma, Y. Segawa, Appl. Phys. Lett. 72, 3270 (1998).

[2] Y. Yoshino, K. Inoue, M. Takeuchi, K. Ohwada, J. Vacuum 51, 601 (1998).

[3] K. Tamura, A. Ohtomo, K. Saikusa, Y. Osaka, T. Makino, Y. Segawa, M. Sumiya, S. Fuke, H. Koinuma, M. Kawasaki, J. Cryst. Growth. 214/215, 59 (2000).

[4] Ü. Özgür, Ya.I. Alivov, C. Liu, A. Teke, M.A. Reshchikov, S. Dogan, V. Avrutin, S.-J. Cho, H. Morkoç, J. Appl. Phys. 98, 041301 (2005).

[5] Y. Chen, F. Jiang, L. Wang, C. Zheng, J. Dai, Y. Pu, W. Fang, J. Cryst. Growth 275, 486 (2005).

[6] G.V. Lashkarev, V.I. Lazorenko, V.A. Karpyna, V.D. Khranovskyy, A.I. Ievtushenko, I.V. Blonsky, I.N. Dmytruk, P.I. Korenyuk, V.A. Baturin, A.Yu. Karpenko, A.Ya. Dan'ko, A.T. Budnikov, M. Godlewski, J. Phys. Chem. Solid State 9, 375 (2008).

[7] A. Ohtomo, H. Kimura, K. Saito, T. Makino, Y. Segawa, H. Koinuma, M. Kawasaki, J. Cryst. Growth 214/215, 284 (2000).

[8] Powder Diffraction File, Card 36-1451, Joint Committee on Powder Diffraction Standards, ICDD, Newtown Square (PA) 2001.

[9] R. Hong, J. Huang, H. He, Z. Fan, J. Shao, Appl. Surf. Sci. 242, 346 (2005).

[10] V. Khranovskyy, R. Minikayev, S. Trushkin, G. Lashkarev, V. Lazorenko, U. Grossner, W. Paszkowicz, A. Suchocki, B.G. Svensson, R. Yakimova, J. Cryst. Growth 308, 93 (2007). 